\title{
Effective Thermal Conductivity Calculation and Measurement of Litz Wire based on the Porous Metal Materials Structure
}

\author{
Xiaomei Liu, David Gerada, Zeyuan Xu, Member, IEEE, Martin Corfield, Chris Gerada, Senior \\ Member, IEEE, Haitao Yu
}

\begin{abstract}
Litz wires are employed in high-frequency electrical machines due to their advantages of reducing the $\mathrm{AC}$ losses, including minimizing the skin effect and the proximity effect. In order to improve the reliability of such machines, and enable accurate thermal predictions at the design stage, accurate calculation of the thermal conductivity of Litz wire is important. In this paper, a calculation method based on the Gasar porous metal materials model is put forward. In this method, a cell model is extracted from the Litz wire, and a thermal resistance network is used to calculate the equivalent thermal conductivity. Following this, two FEA models for the same Litz wire are built, one with actual thermal conductivities for the different constituent materials and another with the calculated equivalent thermal conductivity for an equivalent material, with the two models showing similar thermal characteristics. Finally, an experimental setup is built for measuring the steady-state equivalent thermal conductivity of Litz wire. The apparatus structure and characteristics are described in detail, and the experiment uncertainty and measurement errors are analyzed. Three types of Litz wire are measured in the experimental, and the results from experiment and calculation are consistent.
\end{abstract}

Index Terms-Equivalent thermal conductivity, Gasar porous metal materials, Litz wire, measurement.

\section{INTRODUCTION}

$\mathrm{H}$ igh speed and high pole number electrical machines are increasingly popular due to favorable characteristics such as high power density, compact size, and reduced mass[1]-[3]. However, both higher speeds and higher pole-counts translate to more winding AC losses including skin effect and proximity effect which result in higher losses than those predicted and can severely limit the power output and the efficiency of the machine. In order to mitigate these winding AC loss problems, the use of transposed conductor geometries such as Litz wires is

Manuscript received July 7, 2018; revised October 6, 2018, January 9, 2019, February 27, 2019; accepted March 12, 2019.

$X$. Liu and H. Yu are with the Department of Electrical Engineering, Southeast University, Nanjing 210096, China (e-mail: Ixm812@seu.edu.cn; htyu@seu.edu.cn)

D. Gerada, Z. Y. Xu, M. Corfield, and C. Gerada.are with the Power Electronics, Machines and Control group, University of Nottingham, NG7 2RD, UK, and University of Nottingham Ningbo China, Ningbo 315100, China (David.Gerada@nottingham.ac.uk; Zeyuan.Xu@nottingham.ac.uk; chris.gerada@nottingham.ac.uk). increasingly being applied. Such wires are often bespoke-made for a particular machine design, and can take various forms such as rectangular, round or keyhole-shaped [4]-[10]. The use of rectangular Litz wire within an aerospace generator is shown in Fig. 1.

In the design of high frequency machines, two of the main aspects are the magnetic and thermal domains, which often are limiting factors to achieve the desired power density. The magnetic performance and design associated with Litz wire operation is relatively well understood and has been researched by several authors[4], [8], [11], [12]. The thermal limit is associated with the maximum winding temperature rise and its accurate prediction in the analysis of the thermal characteristics of high frequency electrical machines[8].

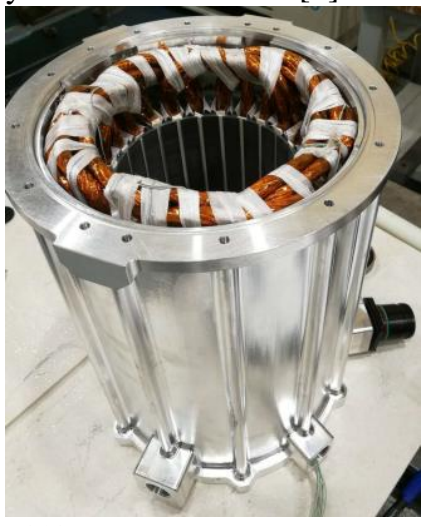

Fig. 1. Litz wire use within an aerospace generator.

The main methods in researching the thermal field of electrical machines are lumped thermal resistance network methods, computational fluid dynamics (CFD), or finite element method (FEM), depending on the type of problem in hand. Combined all-numerical FEA electromagnetic/thermal coupling is applied in [13], while in [14], [15] coupling with lumped thermal resistance networks is adopted. Irrespective of the thermal analysis method used, the accurate thermal properties of the materials that are used in the machine are needed, especially within the slot section, where the majority of losses are typically located[16], and where hotspots leading to machine failures occur.

Thermal conductivities are known at different temperatures for each constituent homogenous material and are typically provided by the material manufacturers. In the case of slots of 
electric machines, the situation is more complex since these are filled with different materials, including randomly placed enameled wire, insulation varnish, insulation paper, and air. If the real structure with different materials is considered when establishing the thermal resistance network or FEA model of slot, it will be very complicated, or in many cases impossible due to the aforesaid random-nature in wire placement. Therefore, in existing literature, homogenization methods are applied, by which the slot section is usually treated as an equivalent homogenous material. Various approaches have been adopted in literature, including homogenization by Milton's method[17], [18], by using equivalent square thermal conductor models, parallel models or using an area weighted average approach [18]-[21], [21]-[25]. More recently the Gasar porous metal material (GPMM) model has been also used in [26]. Compared with traditional mainstream motors using randomly placed strands, the thermal analysis of machines with Litz wire in slots is less common, and the thermal behavior and properties of Litz wire have not received detailed attention in literature. The following two main methods for calculating the thermal resistance of Litz wire are given in literature:

Split resistor model: the authors in reference [27], [28] calculate the thermal resistance of Litz wires considering the single wires and winding layers combined using the split resistor model of round solid wire windings in great detail. Firstly, one Litz wire bundle is transferred into a square Litz wire bundle, then the equivalent thermal resistance of the Litz wire bundle, considering the orthogonal and ortho-cyclic thermal resistances is obtained.

Hashin and Shtrikman (H\&S) approach: Reference [10] discusses two analytical methods used in estimating the ETC of impregnated electrical windings constructed with Litz wire, one using the H\&S approach based on double homogenization for round-profiled enamel-coated conductors, and the other based on establishing an ideal square or rectangular profile for compacted Litz wires with conductors or bundles having square or rectangular outer forms.

As described in reference [28], calculation results obtained by Split resistor model have a higher precision than those by H\&S approach Compared with Split resistor model, both Split resistor model and the method proposed in this paper all translate the actual Litz wire bundle to a square Litz wire bundle. The difference lies in the thermal resistance calculation between bundles in one Litz wire. According to the arrangement of bundles, the orthogonal and ortho-cyclic thermal resistances between bundles are considered in Split resistor model, while for the proposed method, the arrangement of bundles is not required. Similar to the GPMM model, one Litz wire is assumed to be composed of many cells, and the filling material between the bundles is distributed to each cell equally, then for every cell model, based on the equivalent square model, the thermal resistance is obtained.

GPMM can be arranged with regular directional pores of micrometer or millimeter scales with Gasar technology, and the main structure characteristics for the GPMM are: the gap directions are same; the arrangement of the pores is uniform; the distance between the adjacent holes is square or regular triangle, etc. One kind of this porous material is shown in Fig. 2 (a). Litz wire is a type of specialized multi-stranded wire, with strands which are individually insulated and twisted or woven together, and the result of these winding patterns is to equalize the proportion of the overall length over which each strand is at the outside of the conductor[5]. The afore-described structure can in fact be assimilated to a 'GPMM structure' with bare copper in the middle and insulation around the porous copper part, the cross section of which is shown in Fig. 2 (b). For the heat transfer in Litz wire, there is a minimum thermal resistance path in the axial direction, hence there is no significant heat transfer between the different materials. In the radial direction, heat transfer is through different materials. Thus, the cell model of homogenization method based on the structure of GPMM can also be used to calculate the ETC of Litz wire.

The thermal model developed in the paper is used to predict the effective thermal conductivity of Litz wire on its own, and can be applied to various electrical applications. The effects of

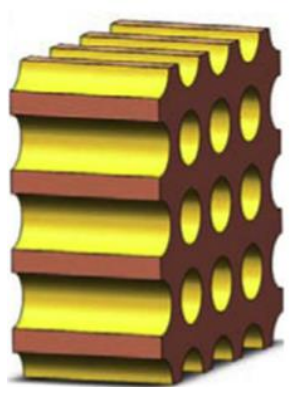

(a)

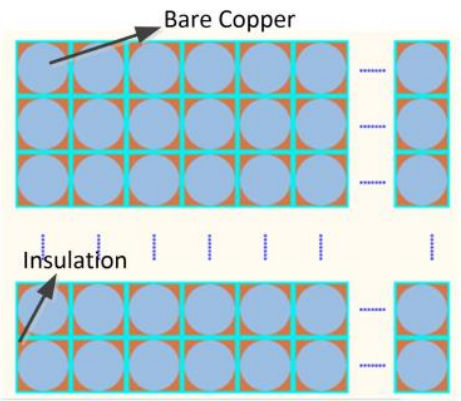

(b)
Fig. 2. Structure model of porous metal material and electric machines' slot. (a) Structure model of porous mental material (b) Slot equivalent structure model of electric machine.

pressure in Litz wire are not considered. Analytical, numerical simulation, as well as experimental techniques for estimating the ETC of Litz wire are discussed in detail and compared with each other. This paper is organized as follows: Section II describes the process of representing a real Litz wire into a representative cell model with a corresponding thermal resistance network for calculating the ETC. In section III, taking an existing Litz wire, thermal FEA is used to reconstruct the real wire model including all strands, as well as the equivalent model based on the analytical calculations of the preceding section to compare the analytical and numerical results. An experimental measurement platform is established in Section IV, and the measurement theory and techniques are described. Three different types of Litz wire are measured and compared to the analytical and numerical calculations. Finally, conclusions are drawn in Section V.

\section{THEORETICAL CALCULATION OF THE ETC BASED ON GPMM MODEL FOR LITZ WIRE}

\section{A. Theoretical Calculation Model of Litz Wire}

In a Litz wire, multiple insulated strands are twisted with each other in a defined repeating pattern. As explained in section I, the structure of the cross section of Litz wire is similar 
to that of GPMM, and hence the method for calculating the thermal conductivity of GPMM is suitable and adaptable for Litz wire.

Through this method, the Litz wire model can be equivalent to an isotropic material with the same thermal conductivity in every direction. Besides, based on the effective medium theory of materials, the effective thermal conductivity region bounded by the H\&S bounds may be divided into internal porosity and external porosity regions[29] when one component is subjected to a steady-state temperature gradient from left to right. Similarly, for the cell unit, the thermal conductivity of copper is higher than the ETC of the insulation, hence it pertains to the external porosity, the heat flux vectors $q$ of this equivalent material being: $q=-\lambda \cdot \operatorname{grad}(T)$, where $\lambda$ is the thermal conductivity $(W /(m \cdot K))$, and $T$ is the temperature.

On the cross section, Litz wire can be divided into a number of cell models, and every cell model contains the bare copper conductor, varnish, and epoxy or air, as shown in shown in Fig. 2 (b). Based on the area equivalent principle, this cell model,

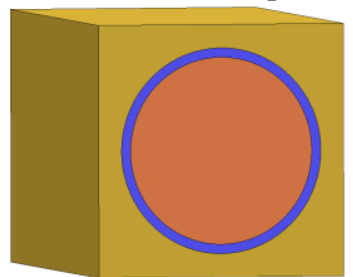

(a)

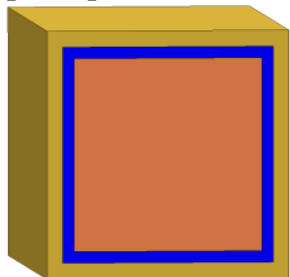

(b)
Fig. 3. Establishment of the equivalent cell model of Litz wire. (a) cell model (b) equivalent cell model.

shown in Fig. 3 F(a) can be transferred to the model in Fig. 3 (b).

\section{B. ETC Calculation of Litz Wire based on Thermal Resistance Network}

The sketch map of the cross-sectional cell model is shown in Fig. 4. distributed from the center to the outside progressively, where $W_{a}$ is the length of the copper cell, $W_{b}$ is the length of the copper and varnish, $W_{c}$ is the length of the whole cell containing copper, varnish, and epoxy (or air), $d$ is the thickness of this cell model. $W_{a}, W_{b}$, and $W_{c}$ are obtained based on the area equivalence principle.

Similar to calculation of electrical resistance network, it is assumed that heat flux flows from the top to the bottom of the cell model, and the thermal resistance network of the cell model is shown in Fig. 5 (a), where $R_{12}$ is part of $R_{2}$. Through calculating the thermal resistance network in Fig. 5 (a), it can be known that $R_{12}$ has a very small impact on the calculation result, so the thermal resistances of $R_{12}$ are ignored, and the thermal resistance network is simplified to that in Fig. 5 (b). Then the heat flux can be assumed to flow in series through the epoxy (or air), varnish, and copper, with $R_{4}, R_{1}, R_{3}$ representing the respective resistances, and in parallel through the epoxy (or air), varnish, and copper simultaneously, with resistances $R_{5}, R_{2}$, and $R_{3}$ respectively.

The constituent thermal resistances $R_{1}$ to $R_{5}$ can be described mathematically as:

$$
\begin{gathered}
\mathrm{R}_{1}=\frac{\left(\mathrm{W}_{\mathrm{b}}-\mathrm{W}_{\mathrm{a}}\right) / 2}{\mathrm{~W}_{\mathrm{a}} \cdot \mathrm{d} \cdot \lambda_{\mathrm{ep}}} \\
\mathrm{R}_{2}=\frac{\mathrm{W}_{\mathrm{b}}}{\left(\mathrm{W}_{\mathrm{b}}-\mathrm{W}_{\mathrm{a}}\right) / 2 \cdot \mathrm{d} \cdot \lambda_{\mathrm{ep}}} \\
\mathrm{R}_{3}=\frac{\mathrm{W}_{\mathrm{a}}}{\mathrm{W}_{\mathrm{a}} \cdot \mathrm{d} \cdot \lambda_{\mathrm{cu}}} \\
\mathrm{R}_{4}=\frac{\left(\mathrm{W}_{\mathrm{c}}-\mathrm{W}_{\mathrm{b}}\right) / 2}{\mathrm{~W}_{\mathrm{b}} \cdot \mathrm{d} \cdot \lambda_{\mathrm{air}}} \\
\mathrm{R}_{5}=\frac{\mathrm{W}_{\mathrm{c}}}{\left(\mathrm{W}_{\mathrm{c}}-\mathrm{W}_{\mathrm{b}}\right) / 2 \cdot \mathrm{d} \cdot \lambda_{\mathrm{air}}}
\end{gathered}
$$

The parameters $m$ and $n$, can be expressed as:

$$
\mathrm{m}=\frac{\mathrm{W}_{\mathrm{a}}^{2} \cdot \mathrm{d}}{\mathrm{W}_{\mathrm{b}}^{2} \cdot \mathrm{d}}, \mathrm{n}=\frac{\mathrm{W}_{\mathrm{b}}^{2} \cdot \mathrm{d}}{\mathrm{W}_{\mathrm{c}}^{2} \cdot \mathrm{d}}
$$

Based on the thermal resistance definition, the equivalent thermal resistance of the cell model in Fig. 4 can be described as:

$$
\mathrm{R}=\frac{\mathrm{d}}{\mathrm{W}_{\mathrm{c}} \cdot \mathrm{W}_{\mathrm{c}} \cdot \lambda_{\mathrm{EQ}}}
$$

From the thermal resistance network, shown in Fig. 5 (b), the equivalent thermal resistance of the cell model in Fig. 4 can be described by:
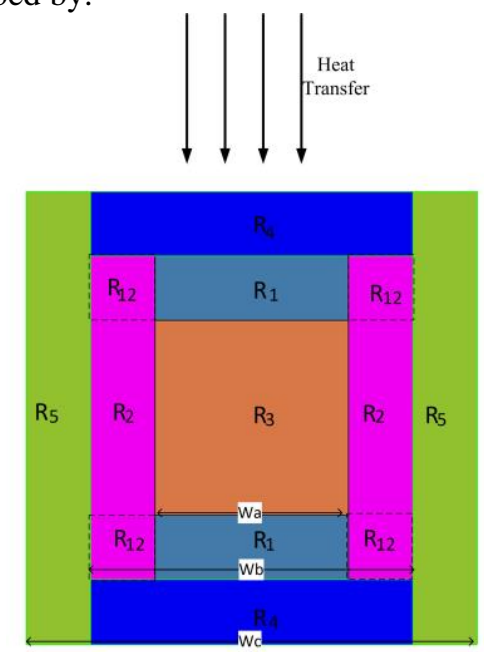

Fig. 4. Cell model of Litz wire.

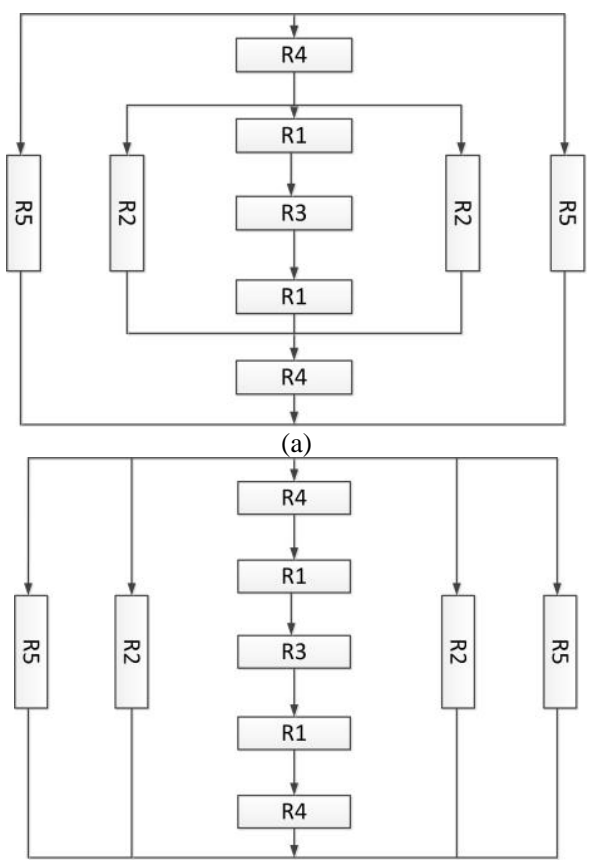

(b) 
Fig. 5. Thermal network of cell model on radial direction (a) considering $R_{12}$ (b) omitting $R_{12}$.

$$
\frac{1}{\mathrm{R}}=\frac{2}{\mathrm{R}_{5}}+\frac{2}{\mathrm{R}_{2}}+\frac{1}{2 \mathrm{R}_{1}+\mathrm{R}_{3}+2 \mathrm{R}_{4}}
$$

Hence, the equivalent heat transfer coefficient of the cell model in Fig. 4 is:

$$
\lambda_{\mathrm{EQ}}=\left(\frac{2}{\mathrm{R}_{5}}+\frac{2}{\mathrm{R}_{2}}+\frac{1}{2 \mathrm{R}_{1}+\mathrm{R}_{3}+2 \mathrm{R}_{4}}\right) \cdot \mathrm{d} / \mathrm{W}_{\mathrm{c}}{ }^{2}
$$

Substituting the thermal resistances of (1)-(5) into (9), the ETC of Litz wire can then be obtained as:

$\lambda_{\mathrm{EQ}}(\mathrm{m}, \mathrm{n})=(1-\sqrt{\mathrm{n}}) \lambda_{\text {air }}+(1-\sqrt{\mathrm{m}}) \lambda_{\mathrm{ep}}+\frac{\sqrt{\mathrm{mn}} \lambda_{\mathrm{ep}} \lambda_{\text {air }} \lambda_{\mathrm{cu}}}{(\sqrt{\mathrm{n}}-\sqrt{\mathrm{mn}}) \lambda_{\mathrm{cu}} \lambda_{\text {air }}+\sqrt{\mathrm{m}}(1-\sqrt{\mathrm{n}}) \lambda_{\mathrm{ep}} \lambda_{\mathrm{cu}}+\sqrt{\mathrm{mn}} \lambda_{\mathrm{ep}} \lambda_{\text {air }}}$

where $\lambda_{e p}, \lambda_{c u}, \lambda_{\text {air }}$ are the thermal conductivity of varnish, copper, and air respectively. If the fill material is epoxy resin between coils, then $\lambda_{\text {air }}$ can be replaced by the thermal conductivity of epoxy resin, $\lambda_{e p-r e}$.

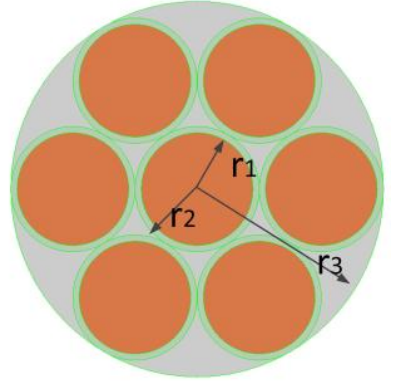

(a)

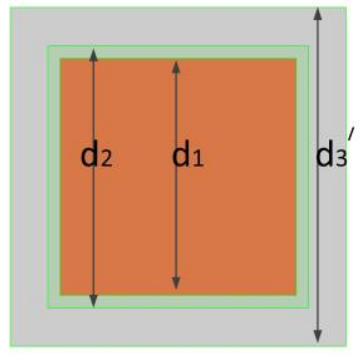

(c)

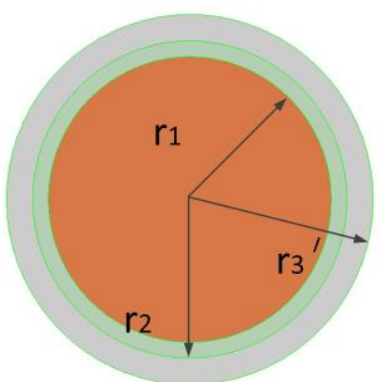

(b)

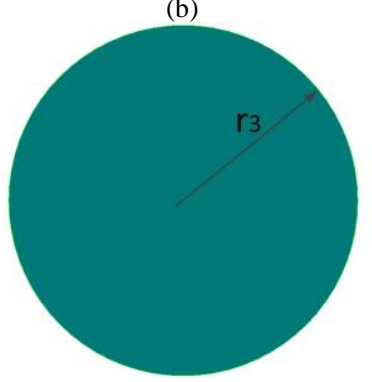

(d)
Fig. 6. The real structure and equivalent structure of Litz wire. (a) Litz wire model (b) cell model (c) equivalent cell model (d) equivalent Litz wire model.

\section{SiMULATION ANALYSIS OF LITZ WIRE}

\section{A. Simulation Model}

To verify the derived theoretical models of the preceding section numerically, the finite element method (FEM) model is applied to simulate the temperature distribution within the Litz wire. Two Litz wire models are established, one with the actual material structure, and another with the equivalent material structure, as obtained from the GPMM model. In order to check the correctness of the ETC of Litz wire, the heat density of each volume together with other boundary conditions such as the thermal convection coefficients and the thermal radiation coefficients are all the same.

The actual Litz wire model is shown in Fig. 6 (a), which consists of seven insulated strands which are twisted, and with the gaps filled with epoxy resin. In order to check the universal applicability, all size data of this Litz wire are random, and one cell of this Litz wire is taken based on the equal area principle. The radii for the copper, enameled strands and Litz wire in Fig. 6 (a) are $r_{1}, r_{2}, r_{3}$ respectively, while the radii for the copper, insulated wire and cell model that is extracted form Fig. 6 (a) are $r_{1}, r_{2}, r_{3}{ }^{\prime}$ respectively, as shown in Fig. 6 (b). where $\mathrm{N} \cdot \pi \mathrm{r}_{3}^{2}=\pi \mathrm{r}_{3}^{2}, N$ being the number of the coils.

The equivalent cube cell model is shown in Fig. 6 (c), the side length for the copper, insulated wire and equivalent cube model being $d_{1}, d_{2}, d_{3}$ respectively. Finally, the radius for the equivalent Litz wire model is $r_{3}$. These data are shown in Table. I. The equivalent model which has the same outer size of the whole Litz wire, but with the derived ETC for the Litz wire is shown in Fig. 6 (d). Besides, when the gaps between the insulated strands are filled with air, the simulation results for actual Litz wire model and the equivalent Litz wire model are also consistent.

TABLE I

Size for Litz Wire Model, Cell Model and Equivalent Cube Model

\begin{tabular}{cc}
\hline \hline Size & Length/mm \\
\hline$r_{1}$ & 4.5 \\
$r_{2}$ & 5 \\
$r_{3}$ & 15 \\
$r_{3}{ }^{\prime}$ & 5.67 \\
$d_{1}$ & 7.974 \\
$d_{2}$ & 8.86 \\
$d_{3}$ & 11.34 \\
\hline
\end{tabular}

The heat density for each copper conductor in the real model is $5 \times 10^{5} \mathrm{~W} / \mathrm{m}^{3}$, and based on the equal area principle, the equivalent heat density for the equivalent model is $3.15 \times 10^{5}$ $\mathrm{W} / \mathrm{m}^{3}$. Based on the theoretical analysis, the ETC for this Litz wire is obtained as, $\lambda_{\text {eq ration }}=1.7557 \mathrm{~W} /\left(\mathrm{m}^{\circ}{ }^{\circ} \mathrm{C}\right)$.

\section{B. Simulation Results Analysis}

With the same boundary conditions, same heat density and convection conditions (the end surfaces being set as perfect insulators, and the convection coefficient for the periphery being set to $\left.60 \mathrm{~W} /\left(\mathrm{m}^{\circ}{ }^{\circ} \mathrm{C}\right)\right)$, one FEA model is set up taking the different thermal conductivities of copper, resin and epoxy in Fig. 6 (a), while another model is set up taking the derived ETC of the equivalent model, which only contains one material with the thermal conductivity of $1.7557 \mathrm{~W} /\left(\mathrm{m} \cdot{ }^{\circ} \mathrm{C}\right)$ as shown in Fig. 6 (d). Through the numerical calculation, the steady state temperature distributions of the real and the equivalent structures are obtained, which are shown in Fig. 7 (a) and Fig. 7 (b), with the temperature distributions at the outer surfaces shown in Fig. 7 (c) and Fig. 7 (d).

From these figures, it can be observed that the temperature distributions for real model and equivalent model are broadly similar: the highest temperature lies in the center of the whole model, and they all go down along the radial direction, the peak temperatures being $69.4^{\circ} \mathrm{C}$, and $69.2^{\circ} \mathrm{C}$ respectively in Fig. 7 (a) and Fig. 7 (b). The average temperature of the outer surface of the real model is about $57.8^{\circ} \mathrm{C}$, with the value of the equivalent model being about $59.2^{\circ} \mathrm{C}$. Due to a large temperature gradient along the circumferential surface of the real model in figure 7(a). The predicted average temperature using the equivalent model is about $1.4^{\circ}$ higher than the real model.

Generally, under the same conditions, the temperature differences $\Delta T$ for the center and outer surface of the equivalent derived model are similar to that of the real model, and since 
the heat densities are the same for these two models, the thermal conductivity from the center to the outer surface are the same for both models. This can explain that the unique variable of the ETC in the equivalent model is close to the real thermal conductivity. The calculation for the ETC for Litz wire, based on the GPMM model is thus reasonable.

The ETC of Litz wire is useful in calculating the thermal

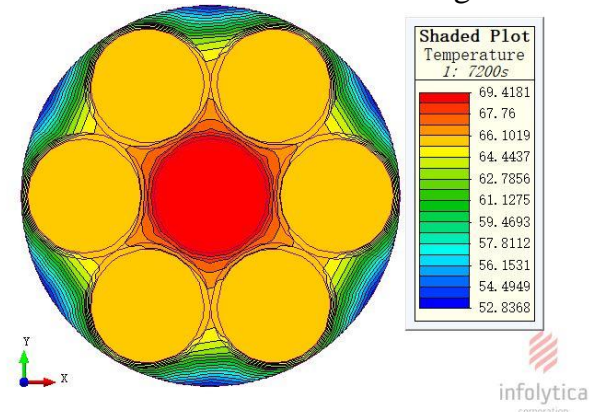

(a)

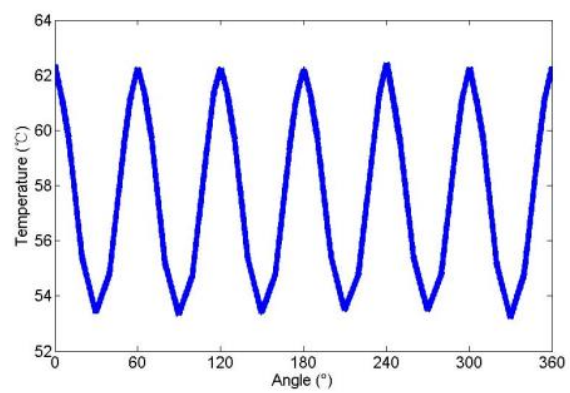

(c) field of the electromagnetic devices. To put this work into context, an application is introduced for a high frequency electric machine. For the electric machine with Litz wire in slots, the equivalent Litz wire model shown in Fig. 6 (d) can be used directly instead of establishing the actual model which will increase the calculation load and time.

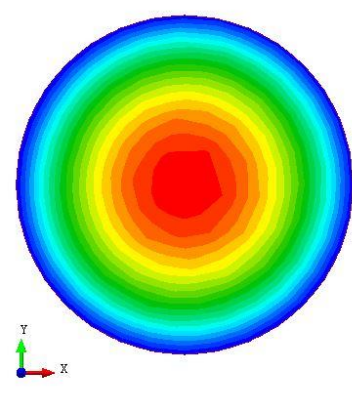

(b)
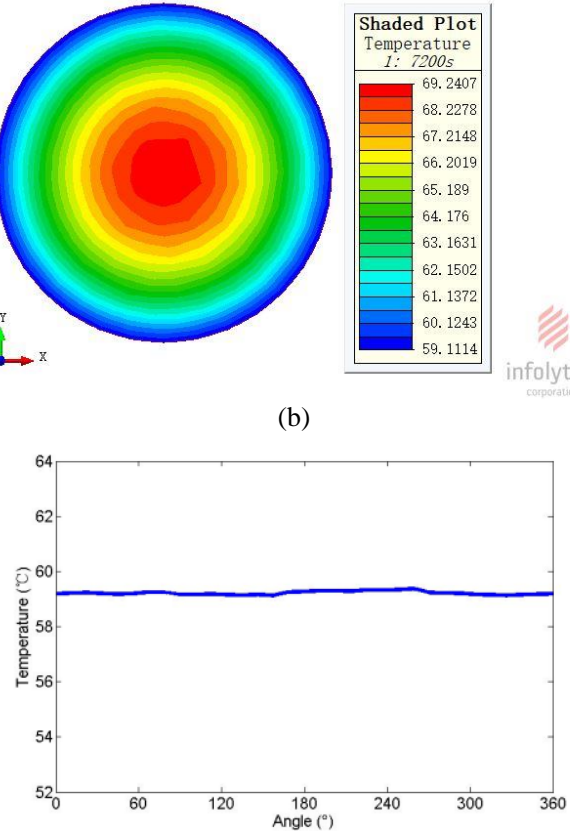

(d)

Fig. 7. Temperature distribution (a) Steady state temperature distribution of real model, (b) Steady state temperature distribution of equivalent model, (c) Outer surface temperature of real model, (d) Outer surface temperature of equivalent model.

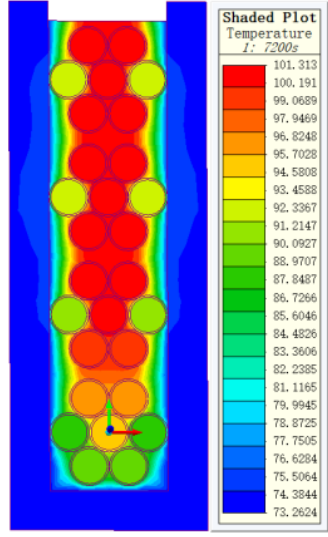

(a)

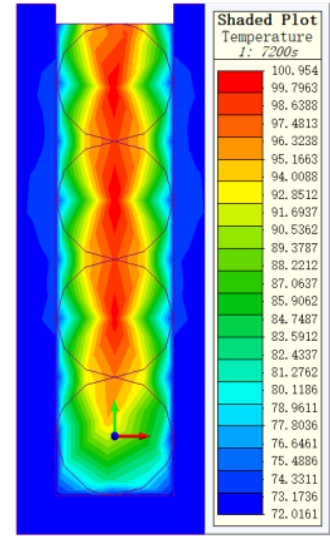

(b)

Fig. 8 Simulation results of Litz wires in an open-slot stator. (a) simulation results of real structure Litz wires in an open-slot (b) simulation results of derived equivalent structure Litz wire in an open -slot.

Four Litz wire real models (the type is shown in Fig. 6 (a)) and four equivalent Litz wire models (as shown in Fig. 6 (d)) are placed in the open-slot of an electric machine respectively, with the slots filled with epoxy resin. Through the numerical calculation, the steady state temperature distributions of the real and the equivalent structures are obtained, which are shown in Fig. 8 (a) and Fig. 8 (b). From the pictures, it can be seen that the temperature distribution is similar, and the peak temperatures are almost the same, being $101.3^{\circ} \mathrm{C}$ and $100.7^{\circ} \mathrm{C}$ respectively. The temperature on the boundaries is almost the same as well, being $73.26^{\circ} \mathrm{C}$ and $72^{\circ} \mathrm{C}$ respectively.

\section{MEASUREMENT OF THE THERMAL CONDUCTIVITY OF LITZ WIRE}

A steady-state, one dimensional heat transfer measurement methodology is used to determine the thermal resistance of Litz wire, and hence calculate the effective thermal conductivity. The experimental setup is based on the well-known ASTM 
D5470 meter bar approach $[31,32]$ and uses two (copper) meter bars, as shown in Fig. 9 (a), to extrapolate/approximate surface temperatures (across a sample under test) and measure the resultant heat flow through a sample. In this configuration, a linear thermal gradient across the contacting surfaces causes heat to flow through the sample, as shown in Fig. 9 (b). The thermocouples are placed equidistantly in the central core of the upper and lower meter bars. There are no thermocouples placed in the aluminum blocks. The various thicknesses of the Litz wire samples are simplified in the representation by the vertical dashed line.

At steady state conditions, measuring the temperature $\left({ }^{\circ} \mathrm{C}\right)$ of each individual thermocouple, using liner least square regression to extrapolate the surface temperatures, and measuring the effective heat flow through the sample, the

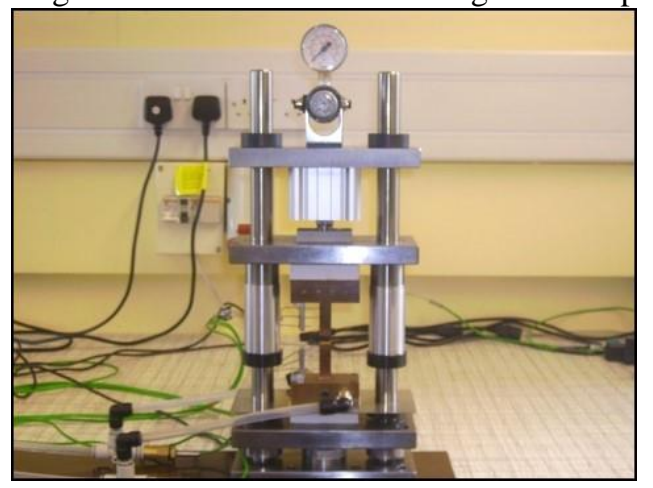

(a)

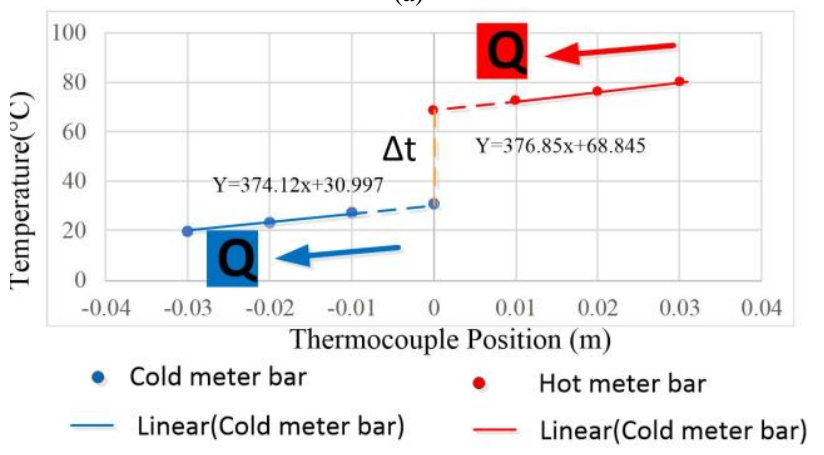

(b)

Fig. 9. ASTM D5470 meter bar approach apparatus. (a) Steady state thermal characterization apparatus, and (b) Representative measurement showing the thermal gradient across a sample under test.

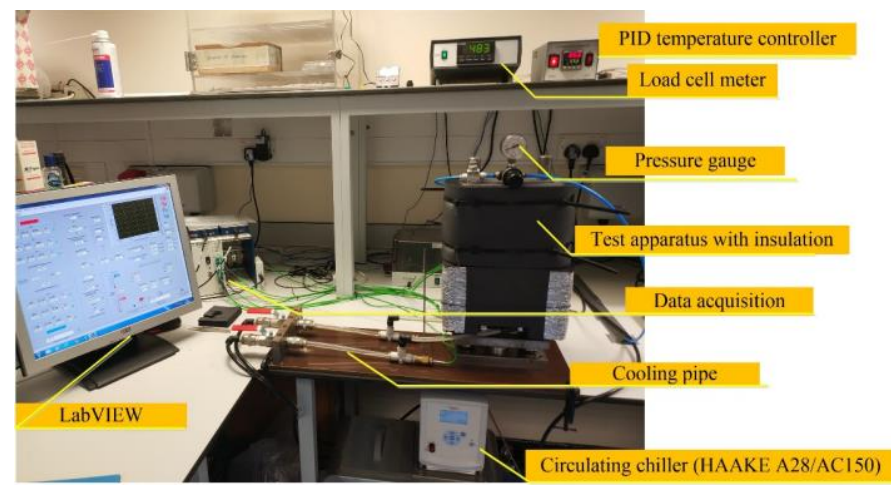

Fig. 10. Experimental setup.

apparent specific thermal resistance $R_{A}\left(\mathrm{~mm}^{2} \cdot \mathrm{K} / \mathrm{W}\right)$ can simply be calculated by:

$$
\mathrm{R}_{\mathrm{A}}=\frac{\Delta \mathrm{T}}{\mathrm{Q}} \mathrm{A}
$$

Where $\Delta T$ (temperature difference) is $\left(T_{\text {high }}-T_{\text {low }}\right)$ the extrapolated contact surface temperatures for the upper- and lower- meter bars/sample, $A$ is the cross-sectional area of the meter bars/sample and $Q$ is the mean average heat flow rate through the sample by conduction $(\mathrm{W})$. Where:

$$
\mathrm{Q}=-\mathrm{KA} \frac{\Delta \mathrm{t}}{\Delta \mathrm{x}}
$$

Where $K$ is the thermal conductivity, $A$ is the cross-sectional area and $\Delta t / \Delta x$ is the thermal gradient in the meter bars. The value of $Q$ used in the thermal resistance calculation is the mean average value of $Q$ for the upper- and lower- meter bars $\left(Q_{\text {high }}+Q_{\text {low }} / 2\right)$ and represents the effective heat flow through the sample under test.
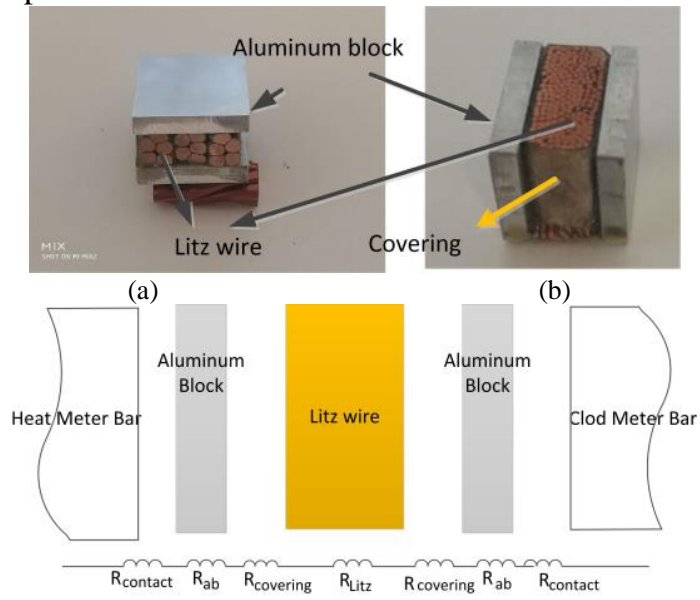

(c)

Fig. 11. Structure of test samples. (a) Sample of Litz wire without covering (b) Sample of Litz wire with covering (c) Thermal resistance network for Litz samples.

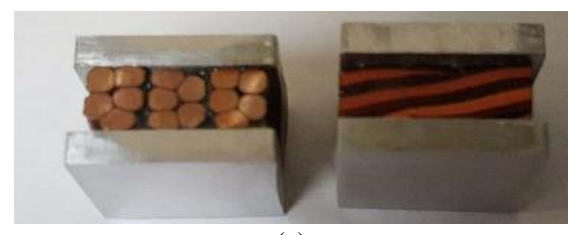

(a)

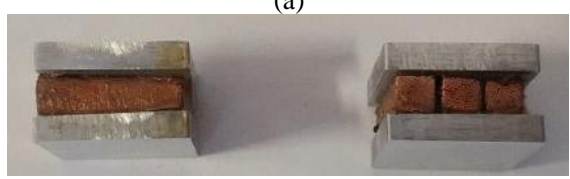

(b)

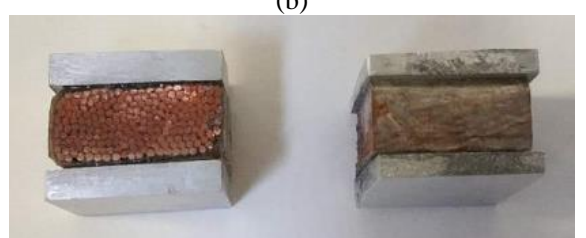

(c)

Fig. 12. Three types of Litz wire samples for the measurement. (a)Type\#1 without external insulation (b)Type\#2 with two layers of $25 \mu \mathrm{m}$ Kapton film (c) Type\#3 with two layers of $63 \mu \mathrm{m}$ Nylon tape.

\section{A. Test Platform}

The upper (hot) meter bar / heat source has integrated (embedded) electrical DC cartridge heaters to supply the heat, while the lower (cold) meter bar / heat sink has internally 
machined cooling channels which are connected to an external circulating chiller (HAAKE A28/AC150) thus maintaining a constant temperature. Both meter bars are machined from blocks of OFHC copper and have three calibrated K-type thermocouples positioned equidistantly from the contacting surfaces, along the length of the bars. A silver conductive thermal compound (CW7100) is used in conjunction with the cartridge heaters and thermocouples to ensure good thermal contact. The meter bars were machined from one block of OFHC to ensure uniformity in thermal conductivity and as a complete unit to eliminate interfaces between the heat source and hot meter bar, and heat sink and cold meter bar. A double action pneumatic cylinder allows samples under test to be compressed between the bars, where the resultant force /

$$
\text { TABLE II }
$$

PARAMETERS FOR THREE TYPES OF LITZ WIRE

\begin{tabular}{cccc}
\hline \hline $\begin{array}{c}\text { Type } \\
\#\end{array}$ & $\begin{array}{c}\text { Bare copper } \\
\text { diameter }(\mathrm{mm})\end{array}$ & $\begin{array}{c}\text { Enamel } \\
\text { thickness }(\mathrm{mm})\end{array}$ & $\begin{array}{c}\text { Wires per square } \\
\text { millimeter }\end{array}$ \\
\hline 1 & 1.8288 & 0.04191 & 0.2728 \\
2 & 0.4 & 0.019 & 3.813 \\
3 & 0.2 & 0.013 & 18.3644 \\
\hline \hline
\end{tabular}

TABLE III

THERMAL RESISTANCE OF DIFFERENT SAMPLES $\left(\left(\mathrm{MM}^{2} \cdot \mathrm{K}\right) / \mathrm{W}\right)$

\begin{tabular}{lllll}
\hline \hline Samples & $R_{m}$ & $\begin{array}{c}2 *\left(R_{\text {ab }}+\right. \\
\left.R_{\text {contact }}\right)\end{array}$ & 2* $R_{\text {covering }}$ & $R_{\text {litz }}$ \\
\hline Type\#1 Sample\#1 & 3308.88 & & - & 2901.13 \\
Type\#1 Sample\#2 & 3097.39 & & & 2689.64 \\
Type\#1 Sample\#3 & 3653.08 & & & 3245.33 \\
Type\#2 Sample\#1 & 2903.81 & 407.75 & 337 & 2159.06 \\
Type\#2 Sample\#2 & 3013.95 & & & 2269.2 \\
Type\#2 Sample\#3 & 3029.12 & & & 2284.37 \\
Type\#3 Sample\#1 & 5139.75 & & 252 & 4480 \\
Type\#3 Sample\#2 & 6590 & & & 5930.25 \\
\hline \hline
\end{tabular}

pressure is accurately measured using a load cell and load cell meter. The meter bars are precision machined for roughness and flatness and aligned to support uniform thermal contact with samples. A $25 \mathrm{~mm}$ thermal insulating block (DURATEC 750 ) is positioned above and below the heat source and heat sink. The frame consists of platens, fitted with liner ball bushings to prevent lateral movement, on precision steel shafts. The platform is thermally insulated using foam insulation (HT/Armaflex) as shown in Fig. 10, to limit radial heat loss and promote one dimensional heat transfer in the axial direction. Also shown in Fig. 10 is the PID temperature controller (for cartridge heaters) and data acquisition hardware/software (LabVIEW) used for thermal characterization.

\section{B. Measurement of Thermal Resistance}

The measurement samples are composed of two aluminum blocks with a section of Litz wire sandwiched in between as shown in Fig. 11 (a) and Fig. 11 (b). Because of their asymmetrical surface, the Litz wire samples are inserted and glued (epoxy) between two aluminum blocks to (1) protect the surfaces of the meter bars and (2) to expedite thermal contact.

Generally, the thermal resistance can be calculated by summation of a series resistance network:

$$
\mathrm{R}_{\text {litz }}=\mathrm{R}_{\mathrm{m}}-2 *\left(\mathrm{R}_{\mathrm{ab}}+\mathrm{R}_{\text {contact }}\right)
$$

Where $R_{\text {Litz }}$ is the thermal resistance of the Litz wire, $R_{m}$ is the thermal resistance of the whole sample, $R_{a b}$ is the thermal resistance of one aluminum block and $R_{\text {contact }}$ is the contact thermal resistance between the aluminum block and the hot/cold meter bar, as shown in Fig. 11 (c).

The thermal conductivity can then be calculated by (14):

$$
\lambda_{\text {Litz }}=\frac{1_{\text {Litz }}}{R_{\text {Litz }}}=\frac{1_{\mathrm{m}}-2 * l_{\mathrm{ab}}}{\mathrm{R}_{\mathrm{Litz}}}=\left(\frac{\mathrm{t}}{\mathrm{RA}}\right)
$$

Where $l_{\text {Litz }}, l_{m}, l_{a b}$ are the thicknesses of the Litz wire, the whole sample, and the aluminum blocks respectively, while $\lambda_{\text {Litz }}$ is the coefficient of thermal conductivity of Litz wire.

In addition, some of the Litz wires samples have a dielectric covering around the external profile, such as Kapton, in order to provide additional electrical insulation as shown in Fig. 11(b). In such a case, for an insulated Litz wire, (13) is modified to include:

$$
\mathrm{R}_{\text {litz }}=\mathrm{R}_{\mathrm{m}}-2 *\left(\mathrm{R}_{\mathrm{ab}}+\mathrm{R}_{\text {contact }}\right)-2 * \mathrm{R}_{\text {covering }}
$$

Measurements were taken at a mean interface temperature $\left(\left(T_{\text {high }}+T_{\text {low }}\right) / 2\right)$ of $50^{\circ} \mathrm{C}$, by adjusting the chiller and PID thermal controller to maximize $Q$, and a constant pressure of $3 \mathrm{MPa}$ to minimize the contact resistance between the test sample(s) and heat flux meter bars. Measurements last until steady state conditions are satisfied, when a temperature variation of $\leq 0.15 \mathrm{~K}$ is successively recorded for each thermocouple over a 15 minutes period. The deviation in temperature is indicative of the system stability as opposed to the absolute tolerance of the thermocouples. The heat flow convergence, (16) (difference in heat flow between the upperand lower- meter bar) is also used to weigh steady state conditions, where a balance of $\leq 5 \%$ was used $(0 \%$ represents a perfect energy balance between upper- and- lower meter bars).

$\mathrm{H}_{\text {balance }}=\min \left(\mathrm{Q}_{\text {up }}, \mathrm{Q}_{\text {down }}\right) / \max \left(\mathrm{Q}_{\text {up }}, \mathrm{Q}_{\text {down }}\right) * 100$

\section{Uncertainty Analysis}

Uncertainty analysis was used to quantify the overall uncertainty in measurements, for the specific thermal resistance and effective thermal conductivity. The overall experimental uncertainty is obtained through use of the Kline and McClintock method which determines the uncertainty of a calculation given certain measurements and the tolerance on those measurements [31], and can be expressed as:

$$
\mathrm{U}_{\mathrm{z}}=\sqrt{\left(\sum_{\mathrm{i}=1}^{\mathrm{n}}\left[\frac{\delta \mathrm{Z}}{\delta \mathrm{X}_{\mathrm{i}}} \mathrm{U}_{\mathrm{i}}\right]^{2}\right)}
$$

Where $U_{z}$ is the root sum square sources of error / overall experimental uncertainty, for each measurement parameter $X_{i}$ and the uncertainty/tolerance in that measurement $U_{i}$. By applying the above expression directly to (14), the uncertainty in the effective thermal conductivity $(\mathrm{K})$ is given by[32]:

$$
\mathrm{U}_{\mathrm{K}}=\left[\left(\frac{\delta \mathrm{K}}{\delta \mathrm{t}}\right)^{2}\left(\mathrm{U}_{\mathrm{t}}\right)^{2}+\left(\frac{\delta \mathrm{K}}{\delta \mathrm{R}}\right)^{2}\left(\mathrm{U}_{\mathrm{R}}\right)^{2}+\left(\frac{\delta \mathrm{K}}{\delta \mathrm{A}}\right)^{2}\left(\mathrm{U}_{\mathrm{A}}\right)^{2}\right]^{1 / 2}
$$

Where $U_{t}$ is the uncertainty in thickness, $U_{R}$ is the uncertainty in thermal resistance and $U_{A}$ is the uncertainty in area of the sample. As the uncertainty in thickness and area can be considered negligible, the $\%$ uncertainty in thermal conductivity then simply parallels the \% uncertainty in thermal resistance given by:

$$
\mathrm{U}_{\mathrm{R}}=\left[\left(\frac{\delta \mathrm{R}}{\delta \Delta \mathrm{T}}\right)^{2}\left(\mathrm{U}_{\Delta \mathrm{T}}\right)^{2}+\left(\frac{\delta \mathrm{R}}{\delta \mathrm{Q}}\right)^{2}\left(\mathrm{U}_{\mathrm{Q}}\right)^{2}\right]^{1 / 2}
$$

Where $U_{\Delta T}$ is the uncertainty in extrapolated surface 
temperatures and $U_{Q}$ is the uncertainty in heat flow.

While it is not intended in the present work to give a rigorous account of the uncertainty analysis used it can be shown that the two main error contributions in the thermal resistance, and therefore thermal conductivity measurements, are due to $\Delta T$ and $Q$. For a given low $\Delta T$, the uncertainty is dominated by the least square regression (goodness of fit) and uncertainty in extrapolated contact temperatures for a sufficiently high value of $Q$. For low values of $Q$ (high $\Delta T$ ) the errors are dominated predominately by system uncertainties such as thermocouple stability.

\section{TABLE IV}

COMPARISON BETWEEN EXPERIMENTAL AND CALCULATION RESULTS

\begin{tabular}{|c|c|c|c|c|c|c|c|c|}
\hline Sample & $\begin{array}{c}l_{\text {Sample }} \\
(\mathrm{mm})\end{array}$ & $\begin{array}{l}l_{\text {Litz }} \\
(\mathrm{mm})\end{array}$ & $\begin{array}{c}R_{\text {litz }} \\
\left(\mathrm{mm}^{2} \mathrm{~K}\right) / \mathrm{W}\end{array}$ & $\begin{array}{c}\lambda_{\text {litz }} \text { of } \\
\text { experiment } \\
(\mathrm{W} /(\mathrm{m} \cdot \mathrm{K}))\end{array}$ & $\begin{array}{c}\text { Mean value of } \\
R_{\text {litz }} \\
(\mathrm{W} /(\mathrm{m} \cdot \mathrm{K}))\end{array}$ & $\begin{array}{c}\text { Experiment } \\
\text { uncertainly } \\
(\%)\end{array}$ & $\begin{array}{c}\lambda_{\text {litz }} \text { of } \\
\text { calculation } \\
(\mathrm{W} /(\mathrm{m} \cdot \mathrm{K}))\end{array}$ & $\begin{array}{c}\text { Variance } \\
\text { between test } \\
\text { and } \\
\text { calculation }\end{array}$ \\
\hline Type\#1 Sample\#1 & 8.09 & 3.59 & 2901.13 & 1.237 & 1.241 & $15.37 \%$ & 1.235 & $5.13 \%$ \\
\hline Type\#1 Sample\#2 & 8.14 & 3.64 & 2689.64 & 1.353 & & $14.85 \%$ & & \\
\hline Type\#1 Sample\#3 & 8.18 & 3.68 & 3245.33 & 1.134 & & $17.42 \%$ & & \\
\hline Type\#2 Sample\#1 & 9.40 & 4.8 & 2159.06 & 2.223 & 2.1274 & $14.09 \%$ & 2.35 & $9.47 \%$ \\
\hline Type\#2 Sample\#2 & 9.31 & 4.71 & 2269.2 & 2.0756 & & $14.59 \%$ & & \\
\hline Type\#2 Sample\#3 & 9.36 & 4.76 & 2284.37 & 2.0837 & & $14.59 \%$ & & \\
\hline Type\#3 Sample\#1 & 9.14 & 4.388 & 4480 & 0.9794 & 0.9996 & $14.6 \%$ & 1.023 & $2.29 \%$ \\
\hline Type\#3 Sample\#2 & 10.8 & 6.048 & 5930.25 & 1.0198 & & $14.59 \%$ & & \\
\hline
\end{tabular}

\section{Measurement of the Thermal Resistance of Litz Wire}

Three variants of Litz wire were tested in this study, as shown in Fig. 12. Type\#1 without additional external dielectric insulation, Type\#2 with two layers of $25 \mu \mathrm{m}$ Kapton film and Type\#3 with two layers of $63 \mu \mathrm{m}$ Nylon tape. Type\#1 comprises 5 strands of AWG13 copper wire, Type\#2 comprises 58 strands of $0.4 \mathrm{~mm}$ copper wire and Type\#3 comprises 200 strands of $0.2 \mathrm{~mm}$ copper wire. The parameters for all three samples are described in Table. II.

Assuming that the aluminum blocks in each sample are identical, firstly, the thermal resistance of the aluminum blocks are measured independently, i.e. without the Litz wire, where the thermal resistances of the aluminum blocks are approximated by $2 *\left(R_{a b}+R_{\text {contact }}\right)$ as described in (13) and (15). The measurement assumes that the thickness (and surface finish) of all Al blocks are constant at $2.25 \mathrm{~mm}$, where the bulk thermal resistance and contact resistance of $2 \mathrm{x}$ aluminum blocks are calculated to be $407.75 \mathrm{~K} / \mathrm{W}$. The thermal resistance of the insulation for Type\#2 and Type\#3 samples is calculated by using $R_{\text {covering }}=l_{\text {covering }} / \lambda_{\text {covering }}$, where $l_{\text {covering }}$ and $\lambda_{\text {covering }}$ are the thickness and thermal conductivity of the insulation respectively, where $\lambda_{\text {covering }}$ for Type\#2 and type\#3 is 0.2 $\mathrm{W} /(\mathrm{m} \cdot \mathrm{K})$ and $1 \mathrm{~W} /(\mathrm{m} \cdot \mathrm{K})$. The thermal resistance measurements for the different samples are shown in Table III.

\section{E. Comparison of the Results between Measurement and Calculation}

The experimental and calculation results are shown in Table. IV, where l_Sample is the overall thickness of the sample, which contains two aluminum blocks and Litz wire, while $l_{\text {Litz }}$ is the independent thickness of the Litz wire, $R_{\text {litz }}$ is the thermal resistance of Litz wire, and $\lambda_{\text {litz }}$ is the thermal conductivity of Litz wire. From Table. IV, it can be seen that the thermal conductivity values obtained by experiment and by the GPMM analytical model proposed in this paper are very similar, where the difference between test and calculation is within $10 \%$. However, the experimental uncertainty is on average around 15\% for the thermal conductivity measurements.
As mentioned previously, the Litz wire samples are fixed between two blocks of $\mathrm{Al}$, where the total thermal resistance comprises the bulk thermal resistance of the Litz wire and aluminum blocks and the contact resistance between aluminum blocks and copper meter bars, and /or Litz wire (insulation) and aluminum blocks. The relatively high experimental uncertainty results from the comparatively low value of heat flow ( $Q_{\text {average }}$ $=2-4 \mathrm{~W}$ ) attainable across the samples with large overall resistance and hence large delta $\mathrm{T}$. In addition, it is also noted that the quality of samples has a significant effect on the precision of the results, most notably the flatness of the aluminum surfaces.

While considerations are given in respect to the bulk thermal resistance and contact resistance of the aluminum blocks and aluminum/copper interfaces, and insulation resistance, in calculating the thermal resistance of the Litz wire, no allowance is made for the bare contact resistance between the Litz wire and aluminum blocks. The nonlinear behavior of resistance and thickness (for the samples) makes it problematic to accurately evaluate this contact resistance. While the thermal contact resistance between the Litz wire and aluminum blocks may be approximated to be similar (or higher) to the self-contact resistance between the two meter-bars $\left(150 \mathrm{~mm}^{2} \mathrm{~K} / \mathrm{W}\right)$ it is not considered in the final calculation for samples without insulation.

\section{CONCLUSION}

The paper has provided an effective method of calculating the equivalent thermal conductivity of Litz Wire, which is a characteristic property of the wire used. The method, based on the Gasar Porous Metal Material (GPMM) model, exacts a cell model from the Litz wire, establishes its thermal resistance network, from which the thermal conductivity of Litz wire is calculated. The aforesaid analytical derivation is firstly verified by numerical FEA method. In the FEA simulation, two models with the same heat source and boundary conditions are established. One model is with the actual Litz wire material structure, while the other model is with an equivalent material 
structure, as derived by the analytical GPMM model. By comparing the peak temperature, and the temperature distribution for these two models the correctness of the analytical model is verified numerically. The analytical model is also verified experimentally using different variants of Litz Wire. The thermal conductivity of the different samples are experimentally determined by measuring the steady-state thermal conductivity. Comparing the experimental data, with the analytical calculation results from GPMM model, it is observed that the variance between the two is within the band of experimental uncertainty, which further verifies the correctness of the method proposed in this paper. Such value of equivalent thermal conductivity is useful for the thermal modelling of the different applications/devices which use Litz Wire, although ultimately the accuracy in temperature prediction is dependent on the specific application and the additional factors, such as pressure, which may need to be considered.

\section{REFERENCES}

[1] L. Papini, T. Raminosoa, D. Gerada, and C. Gerada, "A High-Speed Permanent-Magnet Machine for Fault-Tolerant Drivetrains," IEEE Trans. Ind. Electron., vol. 61, no. 6, pp. 3071-3080, Jun. 2014.

[2] D. Gerada, A. Mebarki, N. L. Brown, C. Gerada, A. Cavagnino, and A. Boglietti, "High-Speed Electrical Machines: Technologies, Trends, and Developments," IEEE Trans. Ind. Electron., vol. 61, no. 6, pp. 29462959, Jun. 2014.

[3] D. Golovanov, L. Papini, D. Gerada, Z. Xu, and C. Gerada, "Multidomain Optimization of High-Power-Density PM Electrical Machines for System Architecture Selection," IEEE Trans. Ind. Electron., vol. 65, no. 7, pp. 5302-5312, Jul. 2018.

[4] M. Rios, G. Venkataramanan, and A. Muetze, "Foil conductor concentrated coil windings for modular permanent magnet AC machines," in IEEE Energy Conversion Congress and Exposition (ECCE), pp. 11911196, 2017.

[5] G. Giovannetti and L. Menichetti, "Litz wire RF coils for low frequency NMR applications," Measurement, vol. 110, no. Supplement C, pp. 116120, Nov. 2017.

[6] S. Hiruma, Y. Otomo, and H. Igarashi, "Eddy Current Analysis of Litz Wire Using Homogenization-Based FEM in Conjunction With Integral Equation," IEEE Trans. Magn., vol. PP, no. 99, pp. 1-4, 2017.

[7] H. Hämäläinen, J. Pyrhönen, J. Nerg, and J. Talvitie, "AC Resistance Factor of Litz-Wire Windings Used in Low-Voltage High-Power Generators," IEEE Trans. Ind. Electron., vol. 61, no. 2, pp. 693-700, Feb. 2014.

[8] E. L. Barrios, A. Ursua, L. Marroyo, and P. Sanchis, "Analytical Design Methodology for Litz-Wired High-Frequency Power Transformers," IEEE Trans. Ind. Electron., vol. 62, no. 4, pp. 2103-2113, Apr. 2015.

[9] R. Wojda and M. K. Kazimierczuk, "Winding Resistance and Power Loss of Inductors with Litz and Solid-Round Wires," IEEE Trans. Ind. Appl., pp. 1-1, 2018.

[10] R. Wrobel, S. Ayat, and J. L. Baker, "Analytical methods for estimating equivalent thermal conductivity in impregnated electrical windings formed using Litz wire, " in IEEE Internal Electric Machines and Drives Conference (IEMDC), pp. 1-8, 2017.

[11] M. A. Eit, F. Bouillault, C. Marchand, and G. Krebs, "2-D Reduced Model for Eddy Currents Calculation in Litz Wire and Its Application for Switched Reluctance Machine," IEEE Trans. Magn., vol. 52, no. 3, pp. 14, Mar. 2016

[12] C. Carretero, "Coupling Power Losses in Inductive Power Transfer Systems With Litz-Wire Coils," IEEE Trans. Ind. Electron., vol. 64, no. 6 , pp. 4474-4482, Jun. 2017.

[13] S. Nategh, H. Zhang, O. Wallmark, A. Boglietti, T. Nassen, and M. Bazant, "Transient Thermal Modeling and Analysis of Railway Traction Motors," IEEE Trans. Ind. Electron., pp. 1-1, 2018

[14] X. Huang, L. Li, B. Zhou, C. Zhang, and Z. Zhang, "Temperature Calculation for Tubular Linear Motor by the Combination of Thermal Circuit and Temperature Field Method Considering the Linear Motion of Air Gap," IEEE Trans. Ind. Electron., vol. 61, no. 8, pp. 3923-3931,
2014.

[15] B. Lockley, B. Lyle, W. MacDonald, M. Noonan, and R. Paes, "Thermal Issues in Operating Large Motors Outside Their Rated Power and Speed Range," IEEE Trans. Ind. Appl., vol. 51, no. 2, pp. 1353-1359, Mar. 2015.

[16] M. van der Geest, H. Polinder, J. A. Ferreira, and D. Zeilstra, "Stator winding proximity loss reduction techniques in high speed electrical machines," in International Electric Machines Drives Conference (IEMDC), 2013, pp. 340-346, 2013.

[17] L. Idoughi, X. Mininger, F. Bouillault, L. Bernard, and E. Hoang, "Thermal Model with Winding Homogenization and FIT Discretization for Stator Slot," IEEE Trans. Magn., vol. 47, no. 12, pp. 4822-4826, 2011.

[18] N. Simpson, R. Wrobel and Phil H. Mellor, "Estimation of Equivalent Thermal Parameters of Impregnated Electrical Windings," IEEE Trans. Ind. Appl., vol. 49, no. 6, pp. 2505-2515, Nov./Dec. 2013.

[19] H. Xuzhen, L. Jiaxi, Z. Chengming, and L. Liyi, "Calculation and Experimental Study on Temperature Rise of a High OverLoad Tubular Permanent Magnet Linear Motor," IEEE Trans. Plasma Sci., vol. 41, no. 5, pp. 1182-1187, 2013.

[20] K. Zhou, J. Pries, and H. Hofmann, "Computationally Efficient 3-D Finite-Element-Based Dynamic Thermal Models of Electric Machines," IEEE Trans. Transp. Electrification, vol. 1, no. 2, pp. 138-149, 2015.

[21] X. Song, N. Mijatovic, S. Zou, B. B. Jensen, and J. Holbøll, "AC Losses and Their Thermal Effect in High-Temperature Superconducting Machines," IEEE Trans. Appl. Supercond., vol. 26, no. 4, pp. 1-5, Jun. 2016.

[22] A. Tessarolo and C. Bruzzese, "Computationally Efficient Thermal Analysis of a Low-Speed High-Thrust Linear Electric Actuator with a Three-Dimensional Thermal Network Approach," IEEE Trans. Ind. Electron., vol. 62, no. 3, pp. 1410-1420, Mar. 2015.

[23] M. Galea, C. Gerada, T. Raminosoa, and P. Wheeler, "A Thermal Improvement Technique for the Phase Windings of Electrical Machines," IEEE Trans. Ind. Appl., vol. 48, no. 1, pp. 79-87, 2012.

[24] G. J. Li, J. Ojeda, E. Hoang, and M. Gabsi, "Thermal-electromagnetic analysis of a fault-tolerant dual-star flux-switching permanent magnet motor for critical applications," IET Electr. Power Appl., vol. 5, no. 6, pp. 503-513, Jul. 2011.

[25] A. Boglietti, E. Carpaneto, M. Cossale, and S. Vaschetto, "Stator-Winding Thermal Models for Short-Time Thermal Transients: Definition and Validation," IEEE Trans. Ind. Electron., vol. 63, no. 5, pp. 2713-2721, May 2016

[26] X. Liu, H. Yu, Z. Shi, L. Huang, T. Xia, and R. Guo, "Porous metal model for calculating slot thermal conductivity coefficient of electric machines," Appl. Therm. Eng., vol. 111, pp. 981-988, 2017.

[27] M. Jaritz and J. Biela, "Analytical model for the thermal resistance of windings consisting of solid or litz wire," in Europe Conference on Power Electronics and Application (ECPEA), pp. 1-10, 2013.

[28] M. Jaritz, A. Hillers, and J. Biela, "General Analytical Model for the Thermal Resistance of Windings Made of Solid or Litz Wire," IEEE Trans. Power Electron., pp. 1-1, 2018.

[29] J. K. Carson, S. J. Lovatt, D. J. Tanner, and A. C. Cleland, "Thermal conductivity bounds for isotropic, porous materials," Int. J. Heat Mass Transf., vol. 48, no. 11, pp. 2150-2158, 2005.

[30] Y. Liu, H. F. Chen, H. W. Zhang, and Y. X. Li, "Heat transfer performance of lotus-type porous copper heat sink with liquid GaInSn coolant, "Int. J. Heat Mass Transf., vol. 80, pp. 605-613, 2015.

[31] H. Nakajima, "Fabrication, properties and application of porous metals with directional pores," Prog. Mater. Sci., vol. 52, no. 7, pp. 1091-1173, 2007.

[32] P. Teertstra, "Thermal Conductivity and Contact Resistance Measurements for Adhesives," proceedings of IPACK, pp. 381-388, 2007.

[33] R. Kempers, P. Kolodner, A. Lyons, and A. J. Robinson, “A high-precision apparatus for the characterization of thermal interface materials," Rev. Sci. Instrum., vol. 80, no. 9, p. 095111, Sep. 2009.

[34] R. J. Moffat, "Describing the uncertainties in experimental results," Exp. Therm. Fluid Sci., vol. 1, no. 1, pp. 3-17, Jan. 1988. 


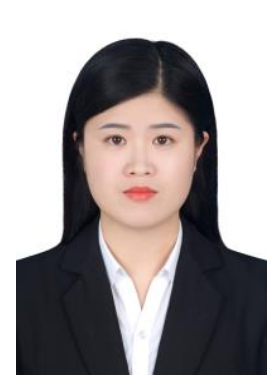

Xiaomei Liu received the B.S degree. in electrical engineering and automation and M.E. degree in electrical engineering from Henan Polytechnic University, Jiaozuo, Henan, China in 2011 and 2014 respectively. From October 2017 to October 2018, she was a joint Ph.D. student with the Department of Electrical Engineering, University of Nottingham, Nottingham, UK, funded by the China Scholarship Council. She is currently pursuing a Ph.D degree in electrical engineering at Southeast University, Nanjing, China, with a focus on permanent magnet synchronous linear motor design and its multi-domain optimization. Her main research interests include high performance motors design and their thermal management.

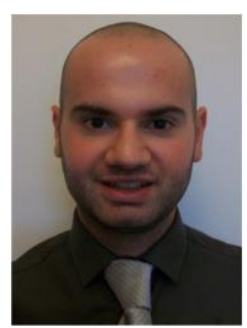

David Gerada received the Ph.D. degree in high-speed electrical machines from University of Nottingham, Nottingham, U.K., in 2012.

From 2007 to 2016, he was with the R\&D Department at Cummins, Stamford, U.K., first as an Electromagnetic Design Engineer (2007-2012), and then as a Senior Electromagnetic Design Engineer and Innovation Leader (2012-2016). At Cummins, he pioneered the design and development of high-speed electrical machines, transforming a challenging technology into a reliable one suitable for the transportation market, while establishing industry-wide-used metrics for such machinery. In 2016, he joined the University of Nottingham as a Senior Fellow in electrical machines, responsible for developing state-of-the-art electrical machines for future transportation which push existing technology boundaries, while propelling the new technologies to higher technology readiness levels. Dr. Gerada is a Chartered Engineer in the U.K. and a member of the Institution of Engineering and Technology.

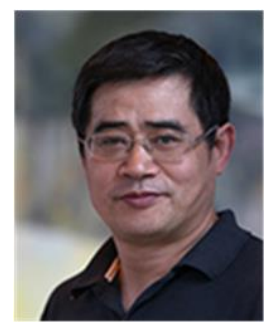

Zeyuan $\mathrm{Xu}$ received the Ph.D. degree in mechanical engineering from the University of Manchester, Manchester, U.K., in 2002. He subsequently worked as a Research Fellow at UMIST, Brunel University, and the University of Nottingham. He is currently a Senior Research Fellow in thermo-mechanical design of high speed electrical machines within the PEMC group at the University of Nottingham, Nottingham, U.K.

His main research interests include turbulent thermo-fluid flow, heat transfer enhancement, thermal management of advanced electrical machines and power electronics, electrical machine structure analysis, rotor dynamics analysis and mechanical design.

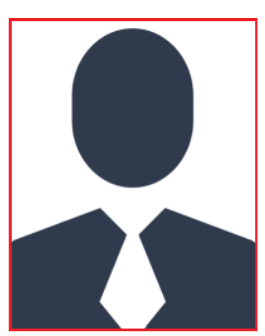

Martin Corfield received the B.Sc. degree in Engineering Science from the University of Hull, Kingston upon Hull, U.K. in 1996, and M.Phil. and Ph.D. degrees in Metallurgy and Materials from the University of Birmingham, Birmingham, U.K. in 1998 and 2003 respectively. He has held research associate posts with the University of Birmingham from 2001 to 2003 (Applied Alloy Chemistry Group) and the University of Sheffield, Sheffield, U.K. from 2003 to 2009 (Electrical Machines and Drives research group) and currently holds the position of Research Fellow (2009...) in the Power Electronics Machines and Control research group within the Department of Electrical and Electronic Engineering at the University of Nottingham, Nottingham, U.K.

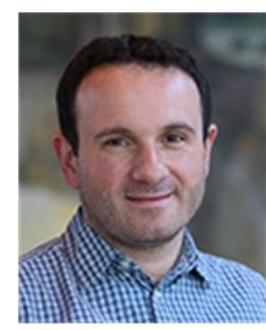

Chris Gerada (M'05) received the Ph.D. degree in numerical modelling of electrical machines from The University of Nottingham, Nottingham, U.K., in 2005. He subsequently worked as a Researcher with The University of Nottingham on high-performance electrical drives and on the design and modelling of electromagnetic actuators for aerospace applications. In 2008, he was appointed as a Lecturer in electrical machines; in 2011, as an Associate Professor; and in 2013, as a Professor at The University of Nottingham. He was awarded a Research Chair from the Royal Academy of Engineering in 2013 and his main research interests include the design and modelling of high-performance electric drives and machines. Prof. Gerada serves as an Associate Editor for the IEEE TRANSACTIONS ON INDUSTRY APPLICATIONS and is the past Chair of the IEEE IES Electrical Machines Committee.

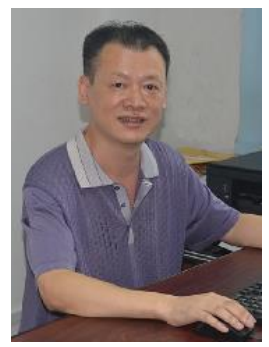

Haitao Yu received the B.E. and M.E. degrees from Chongqing University, Chongqing, China, in 1986 and 1989 respectively, and the Ph.D. degree from Huazhong University of Science and Technology, Wuhan, China, in 1995. He was an associate professor in Huazhong University of Science and Technology in 1997. From 1998 to 2003, he was a visiting scholar in Duke University, USA, and in Canada. He has been a Professor with the School of Electrical Engineering, Southeast University, Nanjing, China, since 2003. His current research interests include linear machine design and control, and wave energy conversion, etc. 